This document was prepared in conjunction with work accomplished under Contract No. DE-AC09-96SR18500 with the U. S. Department of Energy.

\title{
DISCLAIMER
}

This report was prepared as an account of work sponsored by an agency of the United States Government. Neither the United States Government nor any agency thereof, nor any of their employees, nor any of their contractors, subcontractors or their employees, makes any warranty, express or implied, or assumes any legal liability or responsibility for the accuracy, completeness, or any third party's use or the results of such use of any information, apparatus, product, or process disclosed, or represents that its use would not infringe privately owned rights. Reference herein to any specific commercial product, process, or service by trade name, trademark, manufacturer, or otherwise, does not necessarily constitute or imply its endorsement, recommendation, or favoring by the United States Government or any agency thereof or its contractors or subcontractors. The views and opinions of authors expressed herein do not necessarily state or reflect those of the United States Government or any agency thereof. 


\section{IMPLICATIONS OF THE STATISTICAL REVIEW OF THE SIDE-BY-SIDE COMPARISON OF DWPF'S TWO LEEMAN ICPS}

Thomas B. Edwards

January 2005

Statistical Consulting Section

Savannah River National Laboratory

Aiken, SC 29808

Prepared for the U.S. Department of Energy Under Contract Number DEAC09-96SR18500

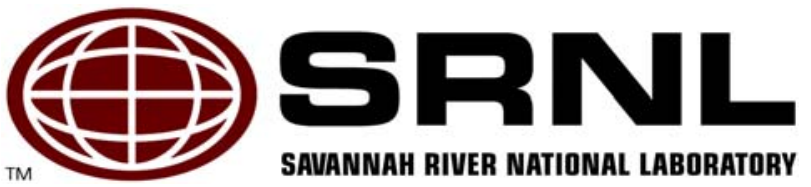


Key Words: statistics, SME, PCCS, dissolution, SRAT

Retention: Permanent

\section{IMPLICATIONS OF THE STATISTICAL REVIEW OF THE SIDE-BY-SIDE COMPARISON OF DWPF'S TWO LEEMAN ICPS}

Thomas B. Edwards

January 2005

Statistical Consulting Section

Savannah River National Laboratory

Aiken, SC 29808

Prepared for the U.S. Department of Energy Under Contract Number DEAC09-96SR18500

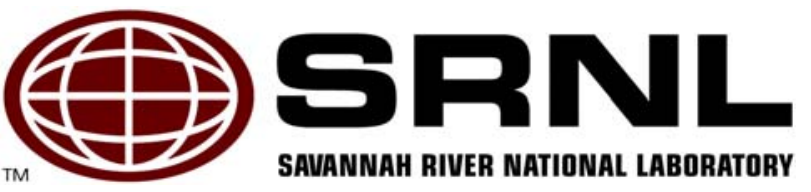


This page was intentionally left blank 


\section{EXECUTIVE SUMMARY}

The Statistical Consulting Section (SCS) of the Savannah River National Laboratory (SRNL) has conducted a statistical evaluation of side-by-side measurement data generated at the Defense Waste Processing Facility (DWPF) using two Leeman Labs Inductively Coupled Plasma - Atomic Emission Spectrometers (ICPs): the production ICP, designated as M-13, and a new Leeman ICP, designated as M-14. The purpose of this report is to document the implications of the statistical evaluation relative to the qualification of the M-14 for use at DWPF. The statistical evaluation conducted by SCS provides the following conclusions:

- Applying the acceptance criteria outlined in the test plan [4] for Slurry Receipt and Adjustment Tank (SRAT) samples prepared using the cold chem method yielded: $\mathrm{SiO}_{2}$ was the only category 1 and $\mathrm{B}_{2} \mathrm{O}_{3}$ and $\mathrm{K}_{2} \mathrm{O}$ were the only category 2 oxides that did not meet their acceptance criteria. The SRAT measurements are used in support of the blending process and are not part of the Slurry Mix Evaporator (SME) acceptability decision of the Product Composition Control System (PCCS). Feedback provided from measurements of SME samples and predictions made in PCCS (predictions for process and product quality as well as waste loading) is expected to lead to adjustments to and improvement in the blending strategy, if improvements are needed. The results from this study lead to the conclusion that employing the M-14 in the analytical process for SRAT product samples will not be a problem for (and should therefore be acceptable to) DWPF Process Chemistry Engineering for sludge/frit blending purposes.

- Applying the acceptance criteria outlined in the test plan [4] yielded: (a) for the SME samples prepared using the fusion method, all category 1 (except for $\mathrm{U}_{3} \mathrm{O}_{8}$ ) and category 2 oxides met their respective criteria, (b) for the SME samples prepared using the mixed acid method, all category 1 and category 2 oxides met their respective acceptance criteria.

- The protocol for using the M-14's mixed acid and fusion measurements (when both were available) for a SME sample explored in this report was the same as that used for the M-13: for $\mathrm{MgO}, \mathrm{Na}_{2} \mathrm{O}$, and $\mathrm{ZrO}_{2}$ the mixed acid measurements were used and for $\mathrm{Al}_{2} \mathrm{O}_{3}, \mathrm{~B}_{2} \mathrm{O}_{3}, \mathrm{CaO}$, $\mathrm{Cr}_{2} \mathrm{O}_{3}, \mathrm{CuO}, \mathrm{Fe}_{2} \mathrm{O}_{3}, \mathrm{~K}_{2} \mathrm{O}, \mathrm{Li}_{2} \mathrm{O}, \mathrm{MnO}, \mathrm{NiO}, \mathrm{SiO}_{2}, \mathrm{TiO}_{2}$, and $\mathrm{U}_{3} \mathrm{O}_{8}$ the fusion measurements were used. Using this protocol, 4 of 6 measurements for eight M-14 calibration blocks were selected, and when the 8 sets of 4 samples were evaluated against the PCCS MAR constraints, they met all of the constraints except for the lower sum of oxides. Three of the 8 calibration blocks failed this PCCS constraint for the M-14. For completeness, the M-13 measurements were used to evaluate SME samples for its eight available calibration blocks, and none of these blocks failed the lower constraint for sum of oxides. As discussed in this report, the sum of oxides for an individual SME sample is expected to fail the lower limit for this constraint twice as often for the M-14 as compared to the M-13. Thus, use of the M-14 may put more pressure on the DWPF Laboratory to repeat their analytical process to support SME acceptability decisions than use of the M-13. The waste loadings determined from the M-14 measurements were on average about 1 point below those determined from the M-13 measurements for these calibration blocks. For sludge/frit systems that are not durability limited, there is high confidence that adequate protection from a poor decision (due to measurement uncertainty) regarding the glass quality of the SME samples is provided by the buffer between the $\Delta \mathrm{G}_{\mathrm{p}}$ value derived from the SME samples and the PAR limit for durability. 
- It should also be noted that the average estimated waste loadings for the M-14 measurements were approximately 1 point smaller than the average waste loading estimated from the M-13 measurements.

- For sludge/frit systems that are not durability limited (i.e., for systems in which the upper waste loading achievable via model predictions is not limited by the durability constraints), there is high confidence that adequate protection from a poor decision (due to ICP measurement uncertainty) regarding the glass quality of the SME samples is provided by the buffer between the durability value derived from the SME samples and the property acceptability region (PAR) limit for durability. This is true for the M-14 ICP as it is for the M-13.

While additional work is needed to fully integrate the M-14 and M-13 ICPs into DWPF's operational systems (see [3] and [4]), use of the M-14 ICP will be adequate for sludge/frit blending and will lead to reliable SME acceptability decisions for product quality. For a sludge/frit system that is limited by a process property prediction such as viscosity or liquidus temperature as waste loading is increased, the SME blending strategy can be adjusted to lessen the impact of an incomplete definition of the M-14's measurement uncertainty on the PCCS acceptability decision until such time as the complete definition of that uncertainty can be determined for the M-14 as well as the M-13. A task is currently underway to address this issue. However, the evaluations presented in this report result in no changes, nor recommendations for changes, to PCCS. 


\section{TABLE OF CONTENTS}

EXECUTIVE SUMMARY iii

LIST OF FIGURES vi

LIST OF TABLES vi vi

LIST OF ACRONYMS

1.0 INTRODUCTION AND BACKGROUND 1

2.0 RESULTS 3

2.1 Cold Chem Comparisons 3

2.2 Impact to DWPF Process Chemistry Engineering's SME Blending 5

2.3 Fusion Comparisons $\quad 5$

2.4 Mixed Acid Comparisons $\quad 7$

2.5 Reporting SME Chemical Compositions 8

2.6 Sum of Oxides Comparisons between ICPs 9

2.7 Acceptability of M-14 and M-13 Measurements for Each Calibration Block 10

2.8 Impact to PCCS Algorithms 12

2.9 Impact Using M-14 Measurements for Estimating Waste Loading at the SME 13

2.10 Viability of M-14 ICP for Production Use 15

2.11 Alternative Protocol for M-14

3.0 CONCLUSIONS 16

4.0 REFERENCES 17 


\section{LIST OF FIGURES}

Figure 1. Cold Chem Sum of Oxides for ARG-1 Samples by ICP......................................... 5

Figure 2. Comparisons of Sums of Oxides for SME Samples................................................. 9

Figure 3. Box Plot Comparisons of Sums of Oxides for SME Samples with 95 and 105\%

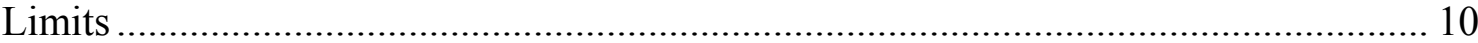

Figure 4. Box Plot Comparisons of SME Waste Loadings by ICP .................................... 14

Figure 5. Comparison Plots of ICP Waste Loadings for Each Calibration Block vs Estimated

SME WL 14

\section{LIST OF TABLES}

Table 1. Highlights of the M-13 versus M-14 Cold Chem Measurements for the SRAT Samples

Table 2. Highlights of ARG-1 Cold Chem Measurements for the M-13 versus the M-14 4

Table 3. Highlights of the M-13 versus M-14 Fusion Measurements for SME Samples 6

Table 4. Highlights of ARG-1 Fusion Measurements for the M-13 versus the M-14 6

Table 5. Highlights of the M-13 versus M-14 Mixed Acid Measurements for SME Samples 7

Table 6. Highlights of ARG-1 Mixed Acid Measurements for the M-13 versus the M-14 8

Table 7. Representing the SME Measurements for the M-13 and M-14 ICPs 8

Table 8. M-13 and M-14 Evaluations Against the PCCS Constraints Using 4 of 6 Replicate Samples to Represent Each Calibration Block 11

Table 9. Estimated WL by SME Batch by ICP Using Best 4 of 6 Along with Estimated SME WLs 


\section{LIST OF ACRONYMS}

$\begin{array}{ll}\text { ARG-1 } & \text { Analytical Reference Glass One } \\ \text { Cold chem } & \text { Cold chemical dissolution and sample preparation method } \\ \text { DWPF } & \text { Defense Waste Processing Facility } \\ \text { ICP } & \text { Inductively Coupled Plasma - Atomic Emission Spectrometer } \\ \text { JMP } & \text { A registered trademark of SAS Institute, Inc. ( statistical software) } \\ \text { LOD } & \text { Limit of Detection } \\ \text { LOQ } & \text { Limit of Quantification } \\ \text { M-13 } & \text { The production Leeman Labs ICP at DWPF } \\ \text { M-14 } & \text { The new Leeman Labs ICP at DWPF } \\ \text { MA } & \text { Mixed acid dissolution and sample preparation method } \\ \text { MAR } & \text { Measurement Acceptability Region in PCCS } \\ \text { MFT } & \text { Melter Feed Tank } \\ \text { NA } & \text { Not Applicable } \\ \text { NL } & \text { Normalized leachate releases (expressed in g/L) } \\ \text { P } & \text { As the unit of measure for viscosity, this represents Poise. } \\ \text { PAR } & \text { Property Acceptability Region in PCCS } \\ \text { PCCS } & \text { Product Composition Control System } \\ & \\ \text { Prep } & \text { preparation } \\ \% \text { RSD } & \text { Percent Relative Standard Deviation } \\ \text { SCS } & \text { Statistical Consulting Section } \\ \text { SME } & \text { Slurry Mix Evaporator } \\ \text { SRAT } & \text { Sludge Receipt and Adjustment Tank } \\ \text { SRNL } & \text { Savannah River National Laboratory } \\ \text { SRS } & \text { Savannah River Site } \\ \text { Std Dev } & \text { Standard Deviation } \\ \text { TTR } & \text { Technical Task Request } \\ \text { WL } & \text { Waste Loading } \\ \text { Wt\% } & \text { Weight percent } \\ \mathrm{T}_{\mathrm{L}} & \text { Liquidus temperature in degrees Celsius } \\ \Delta \mathrm{G}_{\mathrm{p}} & \text { Read as "del G p", this symbol represents the free energy of hydration } \\ & \text { term in units of kcal/100 g glass that is used in the modeling of glass } \\ & \text { durability. } \\ & \\ & \end{array}$


WSRC-TR-2005-00044

Revision 0

This page intentionally left blank. 


\subsection{INTRODUCTION AND BACKGROUND}

The Statistical Consulting Section (SCS) of the Savannah River National Laboratory (SRNL) received data from a series of side-by-side comparisons of two Leeman Labs Inductively Coupled Plasma Atomic Emission Spectrometers (ICPs) conducted by the Defense Waste Processing Facility (DWPF) Laboratory of Waste Laboratory Services. These two Leeman ICPs are designated as M-13 (the current production ICP) and M-14 (the new ICP being evaluated). The data received by SCS were outlined in the test plan [1] describing the series of tests, which involved three sample preparation methods, denoted as: "cold chem," fusion, and mixed acid. A cold chemical (cold chem) preparation is used for samples of the Sludge Receipt and Adjustment Tank (SRAT) product. Fusion and mixed acid dissolutions are used to prepare samples of the Slurry Mix Evaporator (SME).

For each of these three dissolution methods, several types of samples were prepared and measured (for chemical composition) by both ICPs. The samples included process samples (SRAT product for cold chem and SME product for fusion and mixed acid), blanks, and samples of the Analytical Reference Glass One (ARG-1). Groups of these samples (6 groups of SRAT samples and 10 groups of SME samples) corresponding to several different process batches were measured under different calibrations of the two ICPs. The measurements of the process and ARG-1 samples were provided by element (16 elements in all) as weight percent concentrations. For these samples the elemental concentrations were converted to their corresponding oxide concentrations by using the appropriate gravimetric factors.

SCS has conducted a statistical evaluation of the chemical composition measurement data as requested by the test plans ([1] and [2]) and technical task request [3] and in accordance with the task technical and quality assurance plan [4]. The purpose of this report is to document the implications of the statistical evaluation relative to the qualification of the M-14 for use at DWPF, with a more thorough treatment of the statistical tests and comparisons conducted as part of the evaluation available in a sister document ${ }^{1}$. The issues of interest in this report are:

- Evaluate the M-13 and M-14 measurements relative to the acceptance criteria for their differences that were outlined in the supporting test plan [2].

From [2], 4 categories of oxides for these measurements were defined; these are: 1) Element is greater than 0.5 Oxide Wt\% and more than 10 times the Limit of Detection (LOD), 2) Element is less than 0.5 Oxide Wt\% but greater than 10 times the LOD and 0.1 Oxide Wt\%, 3) Element is less than 10 times the LOD or less than 0.1 Oxide Wt\% and 4) Element is below LOD. The criteria are: for category 1, the biases between ICPs are expected to be less than 5\%, for category 2, the biases between the ICPs are expected to be less than 25\%, and no specified criteria for categories 3 and 4.

- Document the anticipated impact of the use of M-14 measurements on the SME Blending Process conducted by DWPF Process Chemistry Engineering.

Based upon the review of these results with members of this engineering group and with their input, provide an assessment of the use of the M-14 for blending of sludge and frit with the SME heel.

1 All of the measurement data that were sent to SCS as well as the details of all of the statistical evaluations conducted by SCS are provided in the memorandum "A Statistical Review of the Side-by-Side Comparisons of DWPF's M-14 and M-13 Leeman ICPs," authored by T. B. Edwards as SRT-SCS-2005-00004 and dated January 12, 2005. 
- Investigate the sum of oxides for the ARG-1 measurements for the cold chem measurements and for the SME samples under the protocol for combining the mixed acid and fusion measurements that is currently being used for the M-13 ICP.

The protocol currently being used with the M-13 ICP at DWPF to represent the composition of a SME sample may be stated as follows: values for $\mathrm{Al}, \mathrm{B}, \mathrm{Ca}, \mathrm{Cr}, \mathrm{Cu}, \mathrm{Fe}, \mathrm{K}, \mathrm{Li}, \mathrm{Mn}, \mathrm{Ni}$, Si, Ti, and $U$ use the fusion results and the values for $\mathrm{Mg}, \mathrm{Na}$, and $\mathrm{Zr}$ use the mixed acid results. The impact of using this same protocol for the M-14's mixed acid and fusion measurements to represent a SME sample on the sum of oxides is discussed.

- Determine the acceptability of the M-14 SME measurements (when both fusion and mixed acid measurements for the SME batch were available) relative to the current Product Composition Control System (PCCS) criteria as defined by [5].

For these acceptability decisions, the protocol for selecting the 4 of 6 samples for each block of measurements as outlined in [6] is followed as well as the protocol for using the mixed acid and fusion results to represent the SME sample measurements. One of the criteria for these decisions involves the sum of oxides, and for these evaluations the sum of oxides is determined by following both of these protocols. These acceptability decisions are made relative to estimates of measurement uncertainty that are currently utilized by PCCS. For completeness, the acceptability decisions for the M-13 SME measurements are also presented as part of the discussion.

- Outline the impact to the PCCS algorithms if the M-14 were to be used to support SME acceptability decisions.

Measurement uncertainties are accounted for in the PCCS algorithms that facilitate DWPF's SME acceptability decisions. These uncertainties estimate the random errors in the elemental concentration measurements of the SME samples that are associated with sampling the SME and analyzing the samples. The uncertainties are expressed as a covariance matrix; the diagonal values of this matrix are estimates of the variances of the random errors for the individual elements and the off-diagonal values are estimates of the covariances between the errors for pairs of these elements. The current PCCS covariance matrix was developed for an earlier production ICP. The investigation into covariance matrices for the M-13 and M-14 ICP are asked for in the technical task request [3], but that investigation is outside the scope of this report. However, there is a need within this report to assess the potential risk to the SME acceptability decisions of using the M-14 with the covariance matrix currently utilized by PCCS.

- Evaluate the anticipated impact of using the M-14 for estimating the waste loading (WL) of SME samples.

Waste loading is an important metric for the DWPF operation. The issue here is: What is the likely effect of the M-14 on the uncertainty of the estimates of WL? 


\subsection{RESULTS}

In this section the highlights of the statistical evaluation of the side-by-side measurements generated by the DWPF Laboratory are presented to address each of the items outlined in the Introduction. The statistical evaluations presented in this report were conducted using JMP Version 5 [7].

\subsection{Cold Chem Comparisons}

The cold chem method provides measurements for all 16 elements of interest. Tables 1 and 2 highlight the comparisons between the M-13 and M-14 measurements (as weight percent oxides) for the SRAT and ARG-1 samples, respectively, prepared by this method. Table 1 presents the M-13 and M-14 average oxide measurements for the SRAT samples (as weight percent of the slurry sample weights) that were involved in this testing. The percent relative difference between each pair of M-13 and M-14 averages is calculated and presented in this table. The percent relative difference entries that are shaded indicate that the two averages are statistically different (at the 5\% significance level). Note that only one of the differences between the M-13 and M-14 averages is statistically significant, the difference for $\mathrm{K}_{2} \mathrm{O}$. In the last column of Table 1, the categories of oxides outlined in the test plan [4] are identified and an assessment of whether or not the corresponding acceptance criterion ${ }^{2}$ for that category was met (i.e., a "yes", "no", or "NA" \{not applicable\} entry in this last column). Thus, the category 1 oxide $\mathrm{SiO}_{2}$ and the category 2 oxides $\mathrm{B}_{2} \mathrm{O}_{3}$ and $\mathrm{K}_{2} \mathrm{O}$ did not meet the acceptance criteria.

There may have been a Si contamination in the sixth block of the cold chem results (see the reference in footnote 2 below). If this block is removed, and the $\mathrm{SiO}_{2}$ comparisons redone, the results are: $0.655 \mathrm{wt} \%$ for the M-13 and $0.596 \mathrm{wt} \%$ for the M-14. Thus, the difference is $9 \%$ but still does not meet the acceptance criteria.

Table 1. Highlights of the M-13 versus M-14 Cold Chem Measurements for the SRAT Samples

(Measurements are in wt\% oxides and NA implies not applicable)

\begin{tabular}{||c|c|c|c|c||}
\hline Oxide & $\begin{array}{l}\text { M-13 } \\
\text { wt\% }\end{array}$ & $\begin{array}{c}\text { M-14 } \\
\text { wt\% }\end{array}$ & $\begin{array}{c}\text { \% Relative } \\
\text { Difference }\end{array}$ & $\begin{array}{c}\text { Category/ } \\
\text { Criterion Met }\end{array}$ \\
\hline $\mathrm{Al}_{2} \mathrm{O}_{3}$ & 2.573 & 2.572 & $-0.06 \%$ & $1 /$ yes \\
\hline $\mathrm{B}_{2} \mathrm{O}_{3}$ & -0.003 & 0.007 & $-358.06 \%$ & $2 /$ no \\
\hline $\mathrm{CaO}$ & 0.501 & 0.503 & $0.40 \%$ & $1 /$ yes \\
\hline $\mathrm{Cr}_{2} \mathrm{O}_{3}$ & 0.034 & 0.036 & $7.54 \%$ & $2 /$ yes \\
\hline $\mathrm{CuO}$ & 0.011 & 0.011 & $-4.86 \%$ & $3 / \mathrm{NA}$ \\
\hline $\mathrm{Fe}_{2} \mathrm{O}_{3}$ & 5.754 & 5.669 & $-1.48 \%$ & $1 /$ yes \\
\hline $\mathrm{K}_{2} \mathrm{O}$ & 0.089 & 0.014 & $-84.85 \%$ & $2 /$ no \\
\hline $\mathrm{Li}_{2} \mathrm{O}$ & 0.008 & 0.003 & $-59.12 \%$ & $3 / \mathrm{NA}$ \\
\hline $\mathrm{MgO}_{\mathrm{MnO}}$ & 0.593 & 0.583 & $-1.63 \%$ & $1 /$ yes \\
\hline $\mathrm{Na}_{2} \mathrm{O}$ & 1.090 & 1.078 & $-1.15 \%$ & $1 /$ yes \\
\hline $\mathrm{NiO}_{\mathrm{SiO}}$ & 3.823 & 3.820 & $-0.09 \%$ & $1 /$ yes \\
\hline $\mathrm{TiO}_{2}$ & 0.292 & 0.289 & $-1.05 \%$ & $1 /$ yes \\
\hline $\mathrm{U}_{3} \mathrm{O}_{8}$ & 0.747 & 0.591 & $-20.92 \%$ & $3 /$ NA \\
\hline $\mathrm{ZrO}_{2}$ & 0.006 & 0.010 & $65.41 \%$ & $1 /$ yes \\
\hline
\end{tabular}

2 The selection of the category for each oxide is discussed in the sister report: "A Statistical Review of the Side-by-Side Comparisons of DWPF's M-14 and M-13 Leeman ICPs,” authored by T. B. Edwards as SRT-SCS-2005-00004 and dated January 12, 2005. 
Table 2 presents similar information for the M-13 and M-14 average measurements from the ARG-1 samples that were prepared using the cold chem method. Only $\mathrm{MgO}$ yielded statistically significant different averages between the M-13 and M-14 cold chem measurements for samples of this standard glass. As seen in this table, the only category 1 oxide that did not meet the acceptance criteria was $\mathrm{K}_{2} \mathrm{O}$. Each of the category 2 oxides in Table 2 met its criteria.

As noted above, there may have been a Si contamination in the sixth block of the cold chem results. If this block is removed, and the $\mathrm{SiO}_{2}$ comparisons redone, the results are: $48.132 \mathrm{wt} \%$ for the $\mathrm{M}-13$ and $47.238 \mathrm{wt} \%$ for the M-14. Thus, the difference is only $1.9 \%$.

Table 2. Highlights of ARG-1 Cold Chem Measurements for the M-13 versus the M-14

(Measurements are in wt\% oxides and NA implies not applicable)

\begin{tabular}{|c|c|c|c|c|}
\hline Oxide & M-13 & M-14 & $\begin{array}{l}\text { \% Relative } \\
\text { Difference }\end{array}$ & $\begin{array}{c}\text { Category/ } \\
\text { Criterion Met }\end{array}$ \\
\hline $\mathrm{Al}_{2} \mathrm{O}_{3}$ & 4.515 & 4.497 & $-0.41 \%$ & $1 /$ yes \\
\hline $\mathrm{B}_{2} \mathrm{O}_{3}$ & 8.602 & 8.600 & $-0.03 \%$ & $1 /$ yes \\
\hline $\mathrm{CaO}$ & 1.383 & 1.399 & $1.16 \%$ & 1/yes \\
\hline $\mathrm{Cr}_{2} \mathrm{O}_{3}$ & 0.097 & 0.108 & $11.84 \%$ & $3 / \mathrm{NA}$ \\
\hline $\mathrm{CuO}$ & 0.008 & 0.005 & $-36.99 \%$ & $3 / \mathrm{NA}$ \\
\hline $\mathrm{Fe}_{2} \mathrm{O}_{3}$ & 14.140 & 13.873 & $-1.89 \%$ & $1 /$ yes \\
\hline $\mathrm{K}_{2} \mathrm{O}$ & 2.874 & 2.680 & $-6.74 \%$ & $1 /$ no \\
\hline $\mathrm{Li}_{2} \mathrm{O}$ & 3.164 & 3.255 & $2.86 \%$ & $1 /$ yes \\
\hline $\mathrm{MgO}$ & 0.855 & 0.833 & $-2.65 \%$ & $1 /$ yes \\
\hline $\mathrm{MnO}$ & 1.853 & 1.814 & $-2.13 \%$ & $1 /$ yes \\
\hline $\mathrm{Na}_{2} \mathrm{O}$ & 11.473 & 11.446 & $-0.24 \%$ & $1 /$ yes \\
\hline $\mathrm{NiO}$ & 1.032 & 1.020 & $-1.23 \%$ & $1 /$ yes \\
\hline $\mathrm{SiO}_{2}$ & 49.129 & 47.655 & $-3.00 \%$ & $1 /$ yes \\
\hline $\mathrm{TiO}_{2}$ & 1.127 & 1.142 & $1.33 \%$ & $1 /$ yes \\
\hline $\mathrm{U}_{3} \mathrm{O}_{8}$ & 0.157 & 0.029 & $-81.19 \%$ & $3 / \mathrm{NA}$ \\
\hline $\mathrm{ZrO}_{2}$ & 0.140 & 0.147 & $5.48 \%$ & $2 /$ yes \\
\hline
\end{tabular}

Figure 1 provides a look at the sum of oxides derived from the measurements of the ARG-1 samples by the two ICPs. Note that, on average, the M-14 delivered approximately a $2 \mathrm{wt} \%$ smaller value than the M-13 for these sums of oxides but that the difference was not statistically significant at the 5\% significance level. If the sixth block of cold chem measurements is excluded, the sums of oxides for the ARG-1 samples were 99.344 and $97.610 \mathrm{wt} \%$, respectively for the M-13 and M-14. Thus, the M-14 delivered a $1.7 \mathrm{wt} \%$ smaller value than the M-13 with the last block of cold chem measurements excluded. 
Figure 1. Cold Chem Sum of Oxides for ARG-1 Samples by ICP

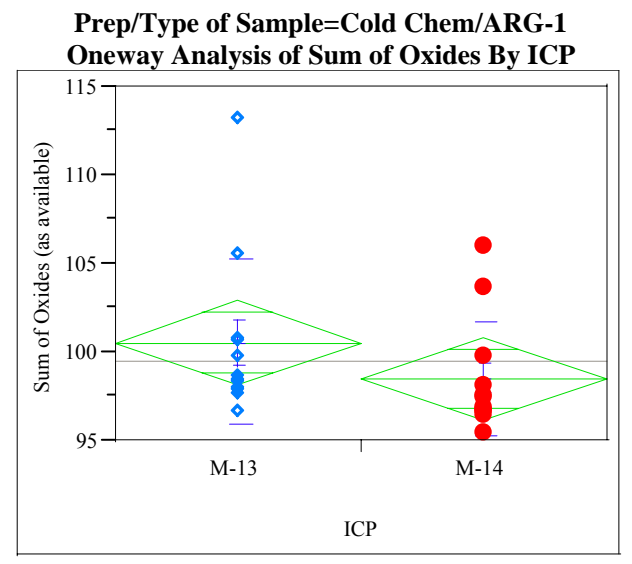

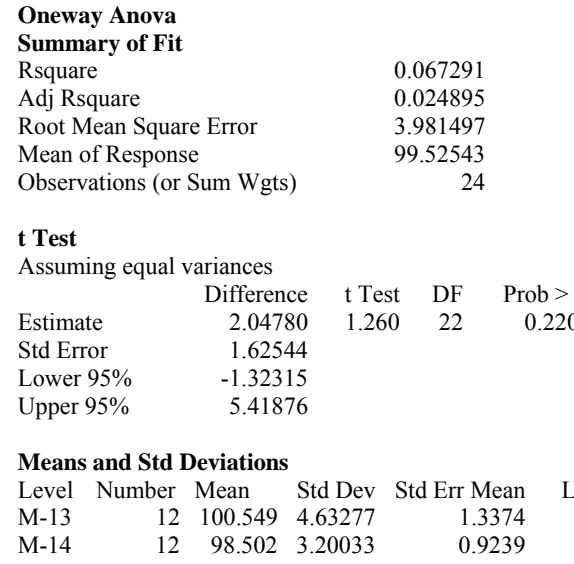
Lower $95 \%$ 97.606 96.468

\subsection{Impact to DWPF Process Chemistry Engineering's SME Blending}

An important input to the SME blending process conducted by DWPF Process Chemistry Engineering is the analysis of the SRAT product that is to be transferred into the SME heel along with an appropriate amount of frit. The composition of the SRAT product is assessed using samples that are measured via the cold chem analytical process. With the results from this study as a guide, measuring the SRAT samples prepared via cold chem using the M-14 ICP would be expected to yield measurements that are comparable in precision and accuracy to those currently being generated using the M-13 ICP.

The SRAT measurements are used in support of the blending process and are not part of the SME acceptability decision of PCCS. Feedback provided from measurements of SME samples and predictions made in PCCS (predictions for process and product quality as well as waste loading) is expected to lead to adjustments to and improvement in the blending strategy, if improvements are needed. The challenges posed by using the M-14 to support the blending process are comparable to the challenges that are presented by the using the M-13. Thus, using the M-14 as part of the analytical process for SRAT product samples will not be a problem for (and should therefore be acceptable to) DWPF Process Chemistry Engineering.

\subsection{Fusion Comparisons}

The fusion method provides measurements for 14 elements of interest. Table 3 and Table 4 highlight the comparisons between the M-13 and M-14 measurements (as weight percent oxides) for the SME and ARG-1 samples, respectively, prepared by this method. Table 3 provides the M-14 and M-13 average measurements for the SME samples that were involved in this testing. The percent relative difference between each pair of M-13 and M-14 averages is calculated and presented in this table. These entries are shaded for those M-13 and M-14 averages that are statistically different (at the 5\% significance level). Thus, the M-13 and M-14 averages are statistically different for several oxides. However, for the major oxides (those oxides in the vitrified SME product at concentrations of at least $0.5 \mathrm{wt} \%$ ), all of these statistically significant differences are no greater than $\sim 3 \%$. In the last column, the 4 categories of oxides are identified and the assessment of whether or not the corresponding acceptance criterion for that category was met (i.e., a "yes", "no", or "NA" (not applicable\} entry in this last column). From this table, all category 1 oxides (except $\mathrm{U}_{3} \mathrm{O}_{8}$ ) and all category 2 oxides met their respective criteria. For $\mathrm{U}_{3} \mathrm{O}_{8}$ the M-14 average is $5.35 \%$ larger than the M-13 average. This difference is not statistically significant at 
the $5 \%$ level, and the slightly higher recovery of $U$ by the M-14 is not seen as a problem in representing this element in the glass.

Table 3. Highlights of the M-13 versus M-14 Fusion Measurements for SME Samples

(SME Measurements are in wt\% oxides and NA implies not applicable.)

\begin{tabular}{|c|c|c|c|c||}
\hline Oxide & $\begin{array}{c}\text { M-13 } \\
\text { Average (wt\%) }\end{array}$ & $\begin{array}{c}\text { M-14 } \\
\text { Average (wt\%) }\end{array}$ & $\begin{array}{c}\text { \% Relative } \\
\text { Difference }\end{array}$ & $\begin{array}{c}\text { Category/ } \\
\text { Criterion Met }\end{array}$ \\
\hline $\mathrm{Al}_{2} \mathrm{O}_{3}$ & 5.589 & 5.572 & $-0.31 \%$ & $1 /$ yes \\
\hline $\mathrm{B}_{2} \mathrm{O}_{3}$ & 4.574 & 4.439 & $-3.04 \%$ & $1 /$ yes \\
\hline $\mathrm{CaO}$ & 1.008 & 1.003 & $-0.53 \%$ & $1 /$ yes \\
\hline $\mathrm{Cr}_{2} \mathrm{O}_{3}$ & 0.081 & 0.070 & $-15.68 \%$ & $3 / \mathrm{NA}$ \\
\hline $\mathrm{CuO}$ & 0.018 & 0.022 & $18.44 \%$ & $3 / \mathrm{NA}$ \\
\hline $\mathrm{Fe}_{2} \mathrm{O}_{3}$ & 11.293 & 11.033 & $-2.36 \%$ & $1 /$ yes \\
\hline $\mathrm{K}_{2} \mathrm{O}$ & 0.176 & 0.239 & $26.51 \%$ & $1 /$ yes \\
\hline $\mathrm{Li}_{2} \mathrm{O}$ & 4.522 & 4.544 & $0.48 \%$ & $1 /$ yes \\
\hline $\mathrm{MgO}_{\mathrm{MnO}}$ & 1.430 & 1.414 & $-1.14 \%$ & $1 /$ yes \\
\hline $\mathrm{Na}_{2} \mathrm{O}$ & 2.052 & 2.023 & $-1.42 \%$ & $1 /$ yes \\
\hline $\mathrm{NiO}_{\mathrm{SiO}}$ & 0.569 & 0.554 & $-2.67 \%$ & $1 /$ yes \\
\hline $\mathrm{TiO}_{2}$ & 50.056 & 48.820 & $-2.53 \%$ & $1 /$ yes \\
\hline $\mathrm{U}_{3} \mathrm{O}_{8}$ & 3.133 & 0.041 & $-4.79 \%$ & $1 /$ NA \\
\hline $\mathrm{ZrO}_{2}$ & \multicolumn{5}{|c|}{ Measurement of this oxide is not available by fusion preparation. } \\
\hline
\end{tabular}

Table 4 presents similar information for the M-14 and M-13 average measurements from the ARG-1 samples that were prepared using the fusion method. Once again, shading is used to identify the oxides for which the M-13 and M-14 yielded statistically different measurement averages for these samples. From Table 4, all of the category 1 and 2 oxides met their respective criteria for these measurements as well.

Table 4. Highlights of ARG-1 Fusion Measurements for the M-13 versus the M-14

(Measurements are in wt\% oxides and NA implies not applicable.)

\begin{tabular}{|c|c|c|c|c||}
\hline Oxide & $\begin{array}{c}\text { M-13 } \\
\text { Avg. }\end{array}$ & $\begin{array}{c}\text { M-14 } \\
\text { Avg. }\end{array}$ & $\begin{array}{c}\text { \% Relative } \\
\text { Difference }\end{array}$ & $\begin{array}{c}\text { Category/ } \\
\text { Criterion Met }\end{array}$ \\
\hline $\mathrm{Al}_{2} \mathrm{O}_{3}$ & 4.489 & 4.500 & $0.25 \%$ & $1 /$ yes \\
\hline $\mathrm{B}_{2} \mathrm{O}_{3}$ & 8.312 & 8.024 & $-3.47 \%$ & $1 /$ yes \\
\hline $\mathrm{CaO}$ & 1.356 & 1.351 & $-0.41 \%$ & $1 /$ yes \\
\hline $\mathrm{Cr}_{2} \mathrm{O}_{3}$ & 0.097 & 0.091 & $-5.90 \%$ & $2 /$ yes \\
\hline $\mathrm{CuO}$ & 0.003 & 0.007 & $115.69 \%$ & $3 / \mathrm{NA}$ \\
\hline $\mathrm{Fe}_{2} \mathrm{O}_{3}$ & 13.701 & 13.453 & $-1.81 \%$ & $1 /$ yes \\
\hline $\mathrm{K}_{2} \mathrm{O}$ & 2.660 & 2.653 & $-0.25 \%$ & $1 /$ yes \\
\hline $\mathrm{Li}_{2} \mathrm{O}$ & 3.137 & 3.138 & $0.03 \%$ & $1 /$ yes \\
\hline $\mathrm{MgO}_{\mathrm{MnO}}$ & 0.822 & 0.816 & $-0.70 \%$ & $1 /$ yes \\
\hline $\mathrm{Na}_{2} \mathrm{O}$ & 1.804 & 1.784 & $-1.10 \%$ & $1 /$ yes \\
\hline $\mathrm{NiO}^{\mathrm{SiO}} \mathrm{Sin}_{2}$ & 1.011 & 0.983 & $-2.74 \%$ & $1 /$ yes \\
\hline $\mathrm{TiO}_{2}$ & 48.095 & 46.781 & $-2.73 \%$ & $1 /$ yes \\
\hline $\mathrm{U}_{3} \mathrm{O}_{8}$ & 1.108 & 1.112 & $0.38 \%$ & $1 /$ yes \\
\hline $\mathrm{ZrO}_{2}$ & 0.031 & -0.008 & $-126.86 \%$ & \\
\hline
\end{tabular}




\subsection{Mixed Acid Comparisons}

The mixed acid method provides measurements for 15 elements of interest. Table 5 and Table 6 highlight the comparisons between the M-13 and M-14 measurements (as weight percent oxides) for the SME and ARG-1 samples, respectively, prepared by this method. Table 5 provides the M-13 and M-14 average measurements for the SME samples that were involved in this testing. The percent relative difference between each pair of M-13 and M-14 averages is calculated and presented as a column of this table. These entries are shaded for those M-13 and M-14 averages that are statistically different (at the 5\% significance level). Thus, several of the oxides yielded M-13 and M-14 averages that are statistically different. Note that none of the major oxides (those oxides in the vitrified SME product at concentrations of at least $0.5 \mathrm{wt} \%$ ) have percent relative differences greater than $2.5 \%$. Also, note that for some of these oxides the M-14 averages are smaller than the M-13 averages, and for others the M-14 is larger. In the last column of Table 5, the 4 categories of oxides are identified and the assessment of whether or not the corresponding acceptance criterion for that category was met (i.e., a "yes", "no", or "NA" \{not applicable $\}$ entry in this last column). Thus, all category 1 oxides met their respective acceptance criteria and $\mathrm{K}_{2} \mathrm{O}$ was the only category 2 oxide that did not meet its respective acceptance criteria.

Table 5. Highlights of the M-13 versus M-14 Mixed Acid Measurements for SME Samples

(SME Measurements are in wt\% oxides and NA implies not applicable.)

\begin{tabular}{||c|c|c|c|c||}
\hline Oxide & $\begin{array}{c}\text { M-13 } \\
\text { Average (wt\%) }\end{array}$ & $\begin{array}{c}\text { M-14 } \\
\text { Average (wt\%) }\end{array}$ & $\begin{array}{c}\text { \% Relative } \\
\text { Difference }\end{array}$ & $\begin{array}{c}\text { Category/ } \\
\text { Criterion Met }\end{array}$ \\
\hline $\mathrm{Al}_{2} \mathrm{O}_{3}$ & 5.468 & 5.560 & $1.67 \%$ & $1 /$ yes \\
\hline $\mathrm{B}_{2} \mathrm{O}_{3}$ & Measurement & \multicolumn{3}{|c||}{ this oxide is not available by mixed acid preparation. } \\
\hline $\mathrm{CaO}$ & 1.031 & 1.057 & $2.50 \%$ & $1 /$ yes \\
\hline $\mathrm{Cr}_{2} \mathrm{O}_{3}$ & 0.080 & 0.066 & $-18.29 \%$ & $2 /$ yes \\
\hline $\mathrm{CuO}$ & 0.018 & 0.014 & $-23.73 \%$ & $3 / \mathrm{NA}$ \\
\hline $\mathrm{Fe}_{2} \mathrm{O}_{3}$ & 11.282 & 11.202 & $-0.71 \%$ & $1 /$ yes \\
\hline $\mathrm{K}_{2} \mathrm{O}$ & 0.286 & 0.078 & $-72.73 \%$ & $2 /$ no \\
\hline $\mathrm{Li}_{2} \mathrm{O}$ & 4.591 & 4.616 & $0.55 \%$ & $1 /$ yes \\
\hline $\mathrm{MgO}_{\mathrm{MnO}}$ & 1.670 & 1.664 & $-0.40 \%$ & $1 /$ yes \\
\hline $\mathrm{Na}_{2} \mathrm{O}$ & 2.039 & 2.037 & $-0.11 \%$ & $1 /$ yes \\
\hline $\mathrm{NiO}^{\mathrm{SiO}} \mathrm{Sin}_{2}$ & 11.521 & 11.498 & $-0.19 \%$ & $1 /$ yes \\
\hline $\mathrm{TiO}_{2}$ & 0.573 & 0.564 & $-1.71 \%$ & $1 /$ yes \\
\hline $\mathrm{U}_{3} \mathrm{O}_{8}$ & 47.644 & 47.182 & $-0.97 \%$ & $1 /$ yes \\
\hline $\mathrm{ZrO}_{2}$ & 0.030 & 0.045 & $53.20 \%$ & $3 / \mathrm{NA}$ \\
\hline
\end{tabular}

Table 6 presents similar information for the M-13 and M-14 average measurements from the ARG-1 samples that were prepared using the mixed acid method. Once again, shading was used to identify those oxides for which the M-13 and M-14 measurement averages were statistically different at the 5\% significance level. As seen in this table, the M-14 yielded measurements for some oxides that were statistically smaller than those from the M-13 and measurements for other oxides that were statistically larger than those from the M-13. Also note that for these measurements, all category 1 and category 2 oxides met their respective acceptance criteria. 
Table 6. Highlights of ARG-1 Mixed Acid Measurements for the M-13 versus the M-14

(Measurements are in wt\% oxides and NA implies not applicable.)

\begin{tabular}{||c|c|c|c|c||}
\hline \hline Oxide & $\begin{array}{c}\text { M-13 } \\
\text { Avg. }\end{array}$ & $\begin{array}{c}\text { M-14 } \\
\text { Avg. }\end{array}$ & $\begin{array}{c}\text { \% Relative } \\
\text { Difference }\end{array}$ & $\begin{array}{c}\text { Category/ } \\
\text { Criterion Met }\end{array}$ \\
\hline $\mathrm{Al}_{2} \mathrm{O}_{3}$ & 4.326 & 4.406 & $1.85 \%$ & $1 /$ yes \\
\hline $\mathrm{B}_{2} \mathrm{O}_{3}$ & Measurement of this oxide is not available by mixed acid preparation. \\
\hline $\mathrm{CaO}$ & 1.363 & 1.396 & $2.41 \%$ & 1 yes \\
\hline $\mathrm{Cr}_{2} \mathrm{O}_{3}$ & 0.096 & 0.088 & $-8.02 \%$ & $2 /$ yes \\
\hline $\mathrm{CuO}$ & 0.003 & -0.002 & $-173.08 \%$ & $3 / \mathrm{NA}$ \\
\hline $\mathrm{Fe}_{2} \mathrm{O}_{3}$ & 13.691 & 13.541 & $-1.09 \%$ & $1 /$ yes \\
\hline $\mathrm{K}_{2} \mathrm{O}$ & 2.772 & 2.462 & $-11.21 \%$ & 1 yes \\
\hline $\mathrm{Li}_{2} \mathrm{O}$ & 3.156 & 3.179 & $0.74 \%$ & $1 /$ yes \\
\hline $\mathrm{MgO}$ & 0.834 & 0.833 & $-0.15 \%$ & $1 /$ yes \\
\hline $\mathrm{MnO}$ & 1.790 & 1.797 & $0.36 \%$ & $1 /$ yes \\
\hline $\mathrm{Na}_{2} \mathrm{O}$ & 11.090 & 11.133 & $0.38 \%$ & $1 /$ yes \\
\hline $\mathrm{NiO}_{\mathrm{SiO}}$ & 1.001 & 1.009 & $0.84 \%$ & $1 /$ yes \\
\hline $\mathrm{SiO}_{2}$ & 45.648 & 45.158 & $-1.07 \%$ & $1 /$ yes \\
\hline $\mathrm{U}_{3} \mathrm{O}_{8}$ & 1.110 & 1.138 & $2.52 \%$ & $1 /$ yes \\
\hline $\mathrm{ZrO}_{2}$ & -0.091 & 0.026 & $-128.90 \%$ & $3 / \mathrm{NA}$ \\
\hline
\end{tabular}

\subsection{Reporting SME Chemical Compositions}

Table 7 provides the combinations of the fusion and mixed acid values from the M-13 ICP that are currently used to represent the SME compositions at DWPF. In the discussions that follow, the M-14 ICP measurements are to be used in the same manner to represent the SME compositions for this second Leeman ICP.

Table 7. Representing the SME Measurements for the M-13 and M-14 ICPs

\begin{tabular}{||c|c||}
\hline Oxide & Represented by \\
\hline $\mathrm{Al}_{2} \mathrm{O}_{3}$ & Fusion \\
\hline $\mathrm{B}_{2} \mathrm{O}_{3}$ & Fusion \\
\hline $\mathrm{CaO}$ & Fusion \\
\hline $\mathrm{Cr}_{2} \mathrm{O}_{3}$ & Fusion \\
\hline $\mathrm{CuO}$ & Fusion \\
\hline $\mathrm{Fe}_{2} \mathrm{O}_{3}$ & Fusion \\
\hline $\mathrm{K}_{2} \mathrm{O}$ & Fusion \\
\hline $\mathrm{Li}_{2} \mathrm{O}$ & Fusion \\
\hline $\mathrm{MgO}$ & Mixed Acid \\
\hline $\mathrm{MnO}$ & Fusion \\
\hline $\mathrm{Na}_{2} \mathrm{O}$ & Mixed Acid \\
\hline $\mathrm{NiO}$ & Fusion \\
\hline $\mathrm{SiO}_{2}$ & Fusion \\
\hline $\mathrm{TiO}_{2}$ & Fusion \\
\hline $\mathrm{U}_{3} \mathrm{O}_{8}$ & Fusion \\
\hline $\mathrm{ZrO}_{2}$ & Mixed Acid \\
\hline \hline
\end{tabular}




\subsection{Sum of Oxides Comparisons between ICPs}

Using the M-13 and M-14 data as indicated in Table 7, a sum of oxides was computed for the SME samples for which fusion and mixed acid measurements were available. Figure 2 provides a comparison of the resulting values from the two ICPs. The comparisons indicate that the M-14 yields sums of oxides that are statistically smaller (at the 5\% significance level) than those generated by the M-13. On average, the M-14 sums are $1.4 \mathrm{wt} \%$ smaller than the sums derived from the M-13 measurements. Also, note that the standard deviations (Std Dev) of the two sets of sums of oxides are very comparable, indicating similar overall precision for the two ICPs.

Figure 2. Comparisons of Sums of Oxides for SME Samples

Type of Sample=SME

Oneway Analysis of Sum of Oxides By ICP

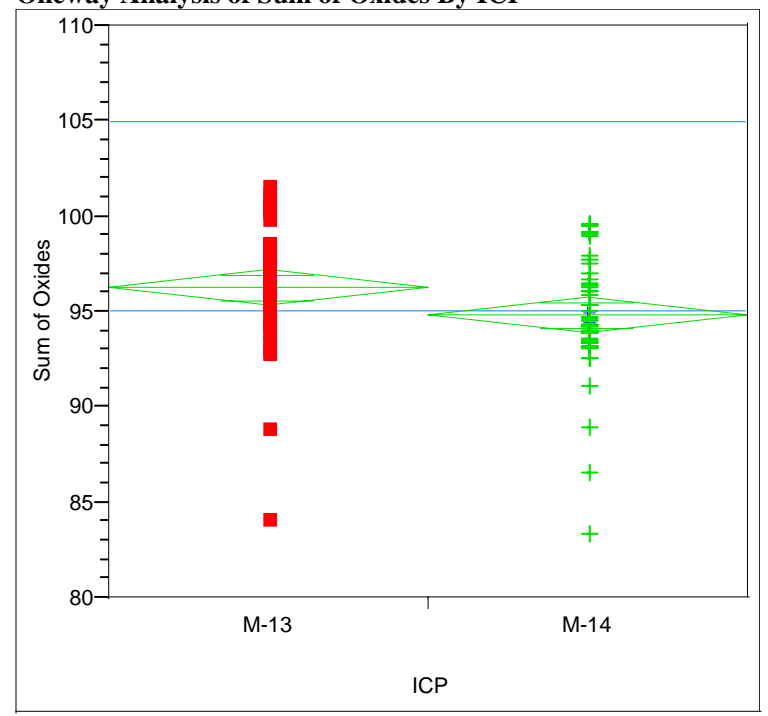

t Test

Assuming equal variances

$\begin{array}{lrlrr} & \text { Difference } & \mathrm{t} \text { Test } & \text { DF } & \text { Prob }>|t| \\ \text { Estimate } & 1.45206 & 2.203 & 92 & 0.0301 \\ \text { Std Error } & 0.65923 & & & \end{array}$

Lower $95 \% \quad 0.14277$

Upper 95\% 2.76134

Level Number $\quad$ Mean $\quad$ Std Dev

$\begin{array}{llll}\mathrm{M}-13 & 47 & 96.2747 & 3.19358\end{array}$

$\begin{array}{llll}\text { M-14 } & 47 & 94.8226 & 3.19789\end{array}$

Figure 3 provides an additional comparison, a comparison of box plots, of the sum of oxides for the SME samples. The top and bottom of each box provides the $75^{\text {th }}$ and $25^{\text {th }}$ percentiles for the set of measurements, respectively, and the line across the box indicates the $50^{\text {th }}$ percentile, or median, for the data. This box plot comparison includes all of the replicates for all of the calibration blocks. Horizontal lines are displayed on the graph to indicate the 95 and $105 \mathrm{wt} \%$ limits imposed on the sum of oxides by PCCS. The graph suggests that the M-14 values are more likely to fail the lower $95 \% \mathrm{wt} \%$ limit than the M-13 values ( $\sim 55 \%$ of the M-14 measurements are below the lower limit versus $\sim 27 \%$ of the M-13 measurements). Thus, the M-14 may fail the sum of oxides constraint approximately twice as often as the M-13 for a single SME sample based upon the results of this study. Note however, that DWPF's process control strategy does not rely on the sums of oxides for individual samples, as discussed in the next section. 
Figure 3. Box Plot Comparisons of Sums of Oxides for SME Samples with 95 and $105 \%$ Limits

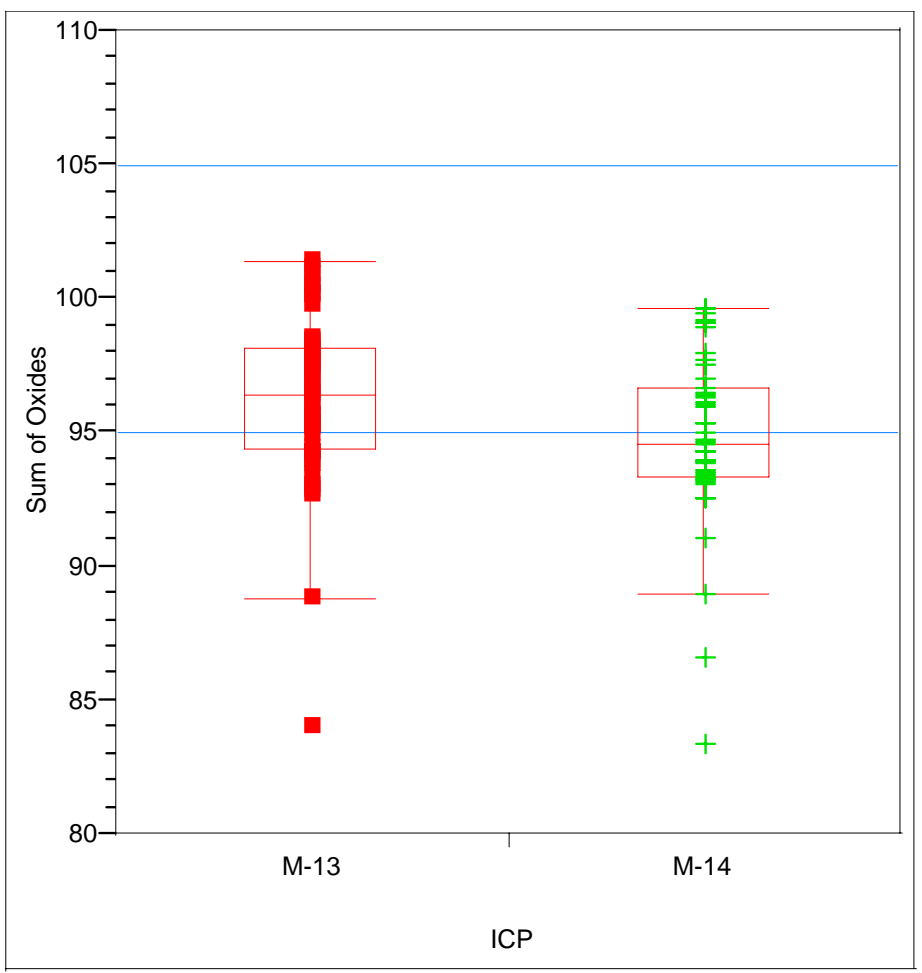

\subsection{Acceptability of M-14 and M-13 Measurements for Each Calibration Block}

The chemical composition measurements of SME samples are critical for process control and product quality assurance as each SME batch is processed. A decision on the acceptability of each SME batch is facilitated by PCCS. In this section, the measurements for each of the M-14 calibration blocks, when both fusion and mixed acid measurements are available, are judged for acceptability against the PCCS constraints. For completeness the M-13 results are also considered in this analysis. For each of the calibration blocks, there were 6 measurements from which 4 were selected. The set of 4 measurements for each calibration block served as input to the PCCS evaluation process. For DWPF operations, the selection protocol involves two steps: 1) selecting which elements to use from which dissolution method (Table 7 was used for this step for both the M-14 and M-13 results) and 2) selecting the best 4 out of 6 digestions (the protocol described in [6] was used for this second step).

The selection of the 4 of 6 replicates in each block, representing a SME batch for which both fusion and mixed acid measurements were available, for input into the PCCS evaluation was conducted as follows. For each such calibration block, the 6 mixed acid replicates were ranked 1 through 6 using the absolute difference of each of their sums of oxides relative to a reference value of $94.5 \mathrm{wt} \%$ for this sum, with the smallest difference being given the ranking of 1. A similar ranking was conducted for the fusion replicates for each calibration block relative to a reference sum of oxides of $83.326 \mathrm{wt} \%$ (excluding the measurements for uranium). For each appropriate calibration block, the 4 highest ranked mixed acid replicates were combined in rank order with the 4 highest ranked fusion replicates to define the 4 of 6 measured compositions for evaluation against the PCCS constraints. The evaluation was conducted using 
the assessment method established in [8] and utilized the Measurement Acceptability Region (MAR) criteria (the more restrictive criteria used by PCCS). All of the PCCS constraints were considered during this evaluation. Each of the available M-14 calibration blocks and each of the available M-13 calibration blocks yielded composition measurements that met all of the PCCS constraints at the current MAR level ${ }^{3}$ except for the lower sum of oxides constraint. Three of the blocks failed this constraint for the M-14 ICP. Thus, use of the M-14 to support the SME acceptability process may put more pressure on the DWPF Laboratory to repeat their analytical process due to low sum of oxides values than use of the M-13.

Table 8 provides a listing of predictions for some of the more important process and product quality properties for each of the calibration sets. The properties that did not meet the PCCS constraints are shaded in this table. The first column of this table identifies the ICP, the second the calibration set; the third column provides the MAR limit for lithium (Li) durability (expressed as a limit on $\Delta \mathrm{G}_{\mathrm{p}}$, the free energy of hydration variable used to model durability [9]); the fourth column provides the value of the free energy of hydration term, $\Delta \mathrm{G}_{\mathrm{p}}$, determined for the sample measurements; the fifth column is the predicted normalized leachate releases (NL) for lithium based upon the $\Delta \mathrm{G}_{\mathrm{p}}$ value (whose unit of measure is in $\mathrm{kcal} / 100 \mathrm{~g}$ of glass); the sixth column is the predicted liquidus temperature $\left(\mathrm{T}_{\mathrm{L}}\right)$ in degrees Celsius $\left({ }^{\circ} \mathrm{C}\right)$, the seventh column is the predicted viscosity in Poise $(\mathrm{P})$, and the last column is the sum of oxides in $w t \%$. Two of the columns associated with durability will be revisited in the next section to support the discussion there. Once again, the average of the 4 of 6 measurements for each and every one of the M-14 and M-13 calibration blocks met all of the constraints when evaluated at the PCCS MAR except for the sum of oxides. This is indicated by the fact that there are only 3 shaded entries in Table 8 (i.e., just the 3 sums of oxides values that did not meet the lower limit for this constraint).

Table 8. M-13 and M-14 Evaluations Against the PCCS Constraints Using 4 of 6 Replicate Samples to Represent Each Calibration Block

\begin{tabular}{||c|c|c|c|c|c|c|c||}
\hline ICP & $\begin{array}{c}\text { SME } \\
\text { Batches }\end{array}$ & $\begin{array}{c}\text { Li } \Delta \text { Gp MAR } \\
\text { Limit }\end{array}$ & $\begin{array}{c}\text { Li } \Delta \mathbf{G p} \\
\text { Value }\end{array}$ & $\begin{array}{c}\text { Predicted NL } \\
{[\mathbf{L i}(\mathbf{g} / \mathbf{L})]}\end{array}$ & $\begin{array}{c}\text { Predicted } \mathbf{T}_{\mathbf{L}} \\
\left({ }^{\circ} \mathbf{C}\right)\end{array}$ & $\begin{array}{c}\text { Predicted } \\
\text { Viscosity }(\mathbf{P})\end{array}$ & $\begin{array}{c}\text { Sum of Oxides } \\
(\mathbf{w t} \%)\end{array}$ \\
\hline M-13 & 293 & -12.395 & -8.989 & 0.53 & 989.4 & 71.7 & 95.5 \\
\hline M-13 & 294 & -12.395 & -8.687 & 0.47 & 995.1 & 79.2 & 96.3 \\
\hline M-13 & 298 & -12.395 & -9.429 & 0.64 & 920.4 & 70.7 & 97.8 \\
\hline M-13 & 298 & -12.395 & -9.511 & 0.66 & 934.2 & 73.3 & 99.7 \\
\hline M-13 & 299 & -12.395 & -9.529 & 0.67 & 912.7 & 66.9 & 97.4 \\
\hline M-13 & 300 & -12.395 & -9.240 & 0.59 & 900.5 & 71.1 & 95.9 \\
\hline M-13 & 300 & -12.395 & -9.928 & 0.79 & 899.7 & 66.0 & 97.1 \\
\hline M-13 & 301 & -12.395 & -9.556 & 0.68 & 943.8 & 62.7 & 98.3 \\
\hline M-14 & 293 & -12.395 & -9.374 & 0.63 & 977.0 & 65.8 & 94.9 \\
\hline M-14 & 294 & -12.395 & -8.946 & 0.52 & 983.2 & 72.7 & 95.7 \\
\hline M-14 & 298 & -12.395 & -10.092 & 0.85 & 905.2 & 63.9 & 97.6 \\
\hline M-14 & 298 & -12.395 & -9.958 & 0.80 & 932.5 & 63.6 & 99.5 \\
\hline M-14 & 299 & -12.395 & -9.628 & 0.70 & 895.4 & 60.4 & 93.7 \\
\hline M-14 & 300 & -12.395 & -9.116 & 0.56 & 908.6 & 90.0 & 96.3 \\
\hline M-14 & 300 & -12.395 & -9.742 & 0.73 & 897.5 & 66.2 & 95.3 \\
\hline M-14 & 301 & -12.395 & -9.743 & 0.73 & 926.6 & 54.8 & 94.8 \\
\hline
\end{tabular}

3 One of the inputs to the MAR is a covariance matrix that estimates the random errors due to sampling and analytical uncertainties. For the assessments discussed in this section, the current covariance matrix of PCCS was used. The next section provides additional discussion of the PCCS covariance matrix. 


\subsection{Impact to PCCS Algorithms}

In the previous section, an acceptability decision was offered for each of the M-14 calibration blocks based upon the measurements of the block and the current PCCS algorithms. One of the inputs to the MAR algorithms of PCCS is the covariance matrix that estimates the random errors in the elemental concentration measurements; these errors are due to sampling and analytical uncertainties. For the assessments discussed in the previous section, the covariance matrix that is currently programmed into PCCS was used. The covariance matrix corresponded to the first production ICP used at DWPF prior to the use of the M-13 ICP. As more information on the performance of the M-13 is generated, there is a task planned (see [3] and [4]) to estimate the covariance matrix to capture the sampling and analytical random errors that would be representative of the M-13's use to provide measurements for PCCS. The need for such a task for the M-13 was identified as part of the evaluation of that Leeman Labs ICP [10]. Note that the contribution to the uncertainty from the sampling errors (historically, the dominant source of uncertainty in the measurement of the SME samples) is associated with the use of "peanut" vials with the Hydragard ${ }^{\circledR}$ sampling system and will remain the same regardless of the ICP being used.

Similarly as information on the performance of the M-14 is generated, its covariance matrix can be estimated to capture the sampling and analytical random errors that would be representative of the M-14's use to provide measurements for PCCS. Such an investigation falls within the scope of the technical task request [3] and corresponding task technical and quality assurance plan [4]. Since the M-14 yielded measurements with comparable precision (i.e., the variation among the M-14 measurements for an element were comparable to the variation in the measurements of the M-13), it may be possible that a single covariance matrix could be developed that is appropriate for both the M-13 and M-14 measurement uncertainties.

The data that were generated by this side-by-side study were not sufficient for the estimation of new covariance matrices. However, efforts are underway to generate the necessary measurements, and a technical task request [3] and corresponding task technical and quality assurance plan [4] are in place for this effort. Once this information is available, an appropriate covariance matrix or matrices for the M-13 and M-14 can be estimated, the impact of the use of these matrices in PCCS can be evaluated, and a decision can then be made on the need to update PCCS to fully integrate a new covariance matrix for the M-13 and/or M-14 or to leave the current covariance matrix as is. The latter decision would be an option if the current covariance matrix were seen to adequately bound the likely M-13 and M-14 errors. However, the evaluations presented in this report result in no changes, nor recommendations for changes, to PCCS.

If the M-14 were used for PCCS assessments before this covariance matrix assessment was completed, what is the likely impact to the reliability of the PCCS acceptability decision? The question may be answered in the same manner that it was answered for the M-13 [10]. The impact due to the covariance matrix on the acceptability region for durability (the critical product quality metric) may be seen by the difference between the Li MAR limit of -12.395 for $\Delta \mathrm{G}_{\mathrm{p}}$ and the Li PAR limit, which has the value -12.781 for $\Delta \mathrm{G}_{\mathrm{p}}$ [5]. For the MAR limit the critical value is shifted $0.386 \Delta \mathrm{G}_{\mathrm{p}}$ units in the positive direction. As seen in this example, the impact of going from the MAR to the PAR limit for durability is a shift in the value of $\Delta \mathrm{G}_{\mathrm{p}}$ by an amount that is typically 0.4 units. The shift in $\Delta \mathrm{G}_{\mathrm{p}}$ limits needed to account for the M-14 MAR or for the M-13 MAR is expected to be close to this value. The values in the third column of Table 8 reveal that for sludge/frit systems that are not durability limited (such as the SB3/Frit 202 or SB3/Frit 418 systems, whose samples were used in this study), there is a large buffer between the $\Delta \mathrm{G}_{\mathrm{p}}$ value derived from the SME samples and the PAR limit ( $>2.3$ units). The difference is many ( $>7$ ) times larger than the shift of $\Delta \mathrm{G}_{\mathrm{p}}$ values in going from the PAR to the MAR as measurement uncertainty is accommodated. For sludge/frit systems that are not durability limited, there is high 
confidence that adequate protection from a poor decision (due to measurement uncertainty) regarding the glass quality of the SME samples is provided by this buffer between the $\Delta \mathrm{G}_{\mathrm{p}}$ value derived from the SME samples and the PAR limit for durability. This is true for the M-14 as it is for the M-13.

If DWPF's sludge/frit system becomes limited by a process property prediction such as viscosity or liquidus temperature as waste loading is increased, then the confidence of satisfying the MAR constraint for this limiting property may be less than the nominal 95\% and will depend upon how close the SME property prediction is to the MAR limit for the property (i.e., the bigger the difference between the property prediction and the MAR limit, the less of an issue this becomes). Thus, as in using measurements from the M-14 or from the M-13 ICP for production control, this issue could be mitigated by a judicious use of the SME blending strategy as part of the risk-based management of the DWPF operation.

\subsection{Impact Using M-14 Measurements for Estimating Waste Loading at the SME}

As seen in Table 3 and Table 4, the data from this study suggest that Li measurements by the M-14 for samples prepared using the fusion method are very comparable to the measurements by the M-13 of the same samples. One issue of concern in this study is the potential impact of the M-14 on estimates of waste loading (WL) that are made from the SME samples. WL is an important metric of DWPF performance; it is estimated for each of the four samples of a SME batch; and an overall estimate of the SME batch itself is determined by averaging the four sample results. The equation for estimating the WL for a SME sample is given by

$$
\mathrm{WL}=100 \cdot\left(1-\frac{\mathrm{Li}_{2} \mathrm{O} /(\text { Sum of Oxides })}{\text { Frit }_{\mathrm{Li}_{2} \mathrm{O} / 100}}\right)
$$

where $\mathrm{Li}_{2} \mathrm{O}$ is the measured wt $\%$ value for this oxide in the SME sample, Sum of Oxides is the sum of oxides in $\mathrm{wt} \%$ for the SME sample, and $\mathrm{Frit}_{\mathrm{Li}_{2} \mathrm{O}}$ is the $\mathrm{wt} \%$ of lithium oxide in the frit lot used to process the sludge in the SME (e.g., Frit 418 for Sludge Batch 3).

Figure 4 is presented to provide some initial insight into this issue. This figure provides a plot of the WLs determined from all the SME samples for all of the calibration blocks for both the M-13 and M-14. In these determinations the values for Frit $_{\mathrm{Li}_{2} \mathrm{O}}$ for the corresponding SME batches were taken from information available in the WG09 server. The means of the two sets of WLs are statistically different (at the 5\% level) with the M-14 WLs being 1 point less than those from the M-13, but there is less variation (although not statistically significant) in the M-14 values than in the M-13's values. Since the $\mathrm{Li}_{2} \mathrm{O}$ values are comparable for the two ICPs, the differences in the sum of oxides for the two ICPs that was noted in Section 2.6 is the reason for the differences in average WLs. 
Figure 4. Box Plot Comparisons of SME Waste Loadings by ICP

Type of Sample=SME with all data used:

Estimated WL By ICP

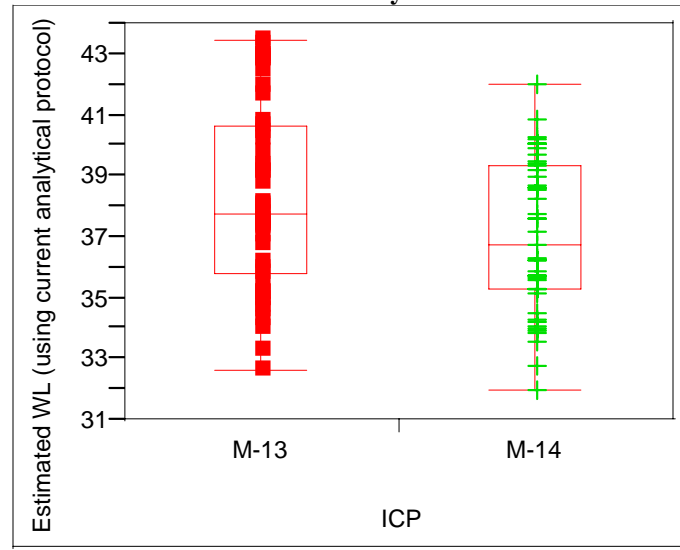

Means and Std Deviations

Level Number Mean

M-13 $\quad 47 \quad 38.2851 \quad 3.02655$

$\begin{array}{llll}\text { M-14 } & 47 \quad 37.0393 & 2.47415\end{array}$
Std Err Mean 0.44147

0.36089
Lower 95\%

37.396

36.313
Upper 95\%

39.174

Figure 5 provides an additional look at WLs generated by the two ICPs. The plot on the left provides a comparison between the M-13 average WL for each batch using the best 4 and the corresponding SME estimates of WL from WG09. The plot on the right provides a comparison between the M-14 average WL for each batch using the best 4 and the corresponding SME estimates. The dashed lines enclosing the diagonal indicates no statistically significant difference (at the 5\% level) between the averages of the two sets of WLs being compared. Thus, the M-13 average WL (38.29\%) is not statistically different from the SME average (38.14\%) while the M-14 average (37.03\%) is statistically different from (i.e., $~ 1$ point lower than) the SME average.

Figure 5. Comparison Plots of ICP Waste Loadings for Each Calibration Block vs Estimated SME WL

$\mathrm{ICP}=\mathrm{M}-13$

Estimated WL vs SME WL

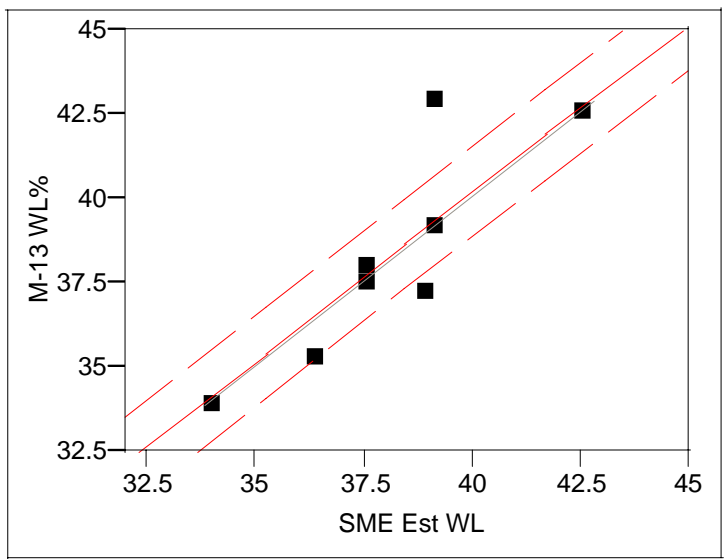

ICP $=\mathrm{M}-14$

Estimated WL vs SME WL

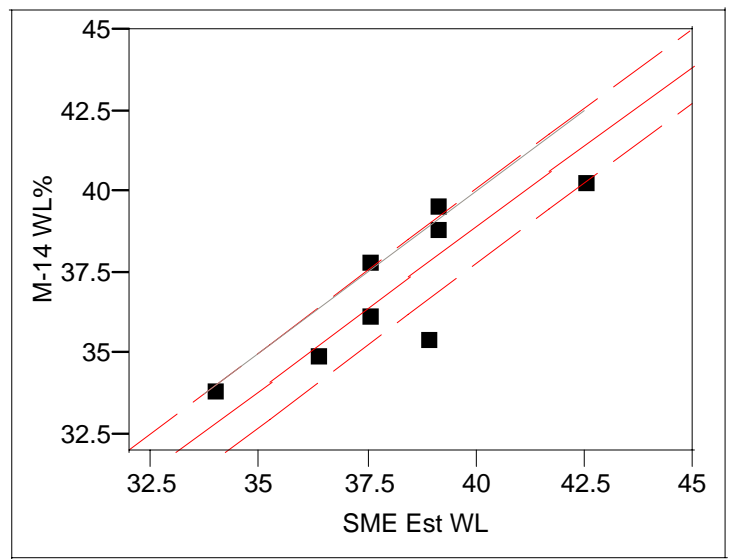


The individual data points plotted in Figure 5 are provided in Table 9, which provides these WL values by calibration block by ICP (while also indicating the original SME batch involved). The WL determined for that SME batch (as recorded in WG09) is also provided in Table 9.

Table 9. Estimated WL by SME Batch by ICP Using Best 4 of 6 Along with Estimated SME WLs

\begin{tabular}{|c|c|c|c||}
\hline $\begin{array}{c}\text { SME } \\
\text { Batch }\end{array}$ & $\begin{array}{c}\text { M-13 } \\
\text { WL\% }\end{array}$ & $\begin{array}{c}\text { M-14 } \\
\text { WL\% }\end{array}$ & $\begin{array}{c}\text { Estimated SME } \\
\text { WL\% }\end{array}$ \\
\hline 293 & 33.87 & 33.75 & 33.97 \\
\hline 294 & 35.24 & 34.84 & 36.36 \\
\hline 298 & 39.17 & 38.76 & 39.14 \\
\hline 298 & 42.89 & 39.46 & 39.14 \\
\hline 299 & 37.17 & 35.36 & 38.89 \\
\hline 300 & 37.50 & 36.08 & 37.54 \\
\hline 300 & 37.94 & 37.77 & 37.54 \\
\hline 301 & 42.51 & 40.21 & 42.54 \\
\hline
\end{tabular}

\subsection{Viability of M-14 ICP for Production Use}

In the discussions above, an array of issues associated with the viability of the M-14 for use as the production ICP at DWPF has been addressed. No roadblocks were encountered at any point in this discussion for such a use of the M-14. While additional work is needed to fully integrate the M-13 and M-14 into DWPF's operational systems, use of the M-14 ICP will be adequate for sludge/frit blending and will lead to reliable SME acceptability decisions for product quality.

For a sludge/frit system that is limited by a process property prediction such as viscosity or liquidus temperature as waste loading is increased, the SME blending strategy can be adjusted to lessen the impact of an incomplete definition of the M-14's MAR on the acceptability decision until such time as the complete definition can be determined. This strategy was also offered for the use of the M-13 ICP [10].

For the SME results, there was a tendency for the M-14 to yield a lower sum of oxides than the M-13. Thus, use of the M-14 to support the SME acceptability process may put more pressure on the DWPF Laboratory to repeat their analytical process due to low sum of oxides values than use of the M-13.

\subsection{Alternative Protocol for M-14}

As noted above, Table 7 defined the protocol for using the M-14 fusion and mixed acid measurements to represent a SME sample. Could the M-14 results be improved if a different protocol was used for the M-14 measurements? As an answer to that question, the M-14 protocol was changed to use mixed acid for $\mathrm{Ca}, \mathrm{Fe}, \mathrm{Li}$, and $\mathrm{U}$ with the other elements remaining as defined in Table 7 . Using this modified protocol, leads to the following results:

- $\quad$ Over the set of all SME samples, the M-14 average sum of oxides (95.38 wt\%) is 0.89 wt $\%$ less than the M-13 value (96.27 wt $\%)$. The M-14 average WL (37.04\%) is 1.25 points less than the M-13 value (38.29\%). 
- $\quad$ Using the best 4 of 6 to represent each SME batch for PCCS evaluation, only 1 of the 8 M-14 blocks failed the lower sum of oxides constraint sum of oxides. This is an improvement over the 3 blocks that failed under the protocol of Table 7.

These results suggest that a modification to the M-14 protocol for using the fusion and mixed acid measurements to represent the SME samples may be beneficial.

\subsection{CONCLUSIONS}

Applying the acceptance criteria outlined in the test plan [4] for SRAT samples prepared using the cold chem method yielded: $\mathrm{SiO}_{2}$ was the only category 1 and $\mathrm{B}_{2} \mathrm{O}_{3}$ and $\mathrm{K}_{2} \mathrm{O}$ were the only category 2 oxides that did not meet their acceptance criteria. The SRAT measurements are used in support of the blending process and are not part of the SME acceptability decision of PCCS. Feedback provided from measurements of SME samples and predictions made in PCCS (predictions for process and product quality as well as waste loading) is expected to lead to adjustments to and improvement in the blending strategy, if improvements are needed. The results from this study lead to the conclusion that employing the M-14 in the analytical process for SRAT product samples will not be a problem for (and should therefore be acceptable to) DWPF Process Chemistry Engineering for sludge/frit blending purposes.

For the fusion SME measurements, several oxides yielded M-14 and M-13 averages that were statistically different (at the 5\% significance level). For the major oxides, the \% relative differences between the two ICPs are all less than $5 \%$ except for $\mathrm{U}_{3} \mathrm{O}_{8}$, for which the difference is $5.35 \%$. Several of the oxides yielded M-14 and M-13 averages for the mixed acid SME data that were statistically different (at the 5\% significance level). The major oxides have $\%$ relative differences between the two ICPs that are all less than $5 \%$.

Applying the acceptance criteria outlined in the test plan [4] yielded: (a) for the SME samples prepared using the fusion method, all category 1 (except for $\mathrm{U}_{3} \mathrm{O}_{8}$ ) and category 2 oxides met their respective criteria, (b) for the SME samples prepared using the mixed acid method, all category 1 and category 2 oxides met their respective acceptance criteria.

The protocol for using the M-14's mixed acid and fusion measurements (when available) for a SME sample explored in this report was the same as that used for the M-13: for $\mathrm{MgO}, \mathrm{Na}_{2} \mathrm{O}$, and $\mathrm{ZrO}_{2}$ the mixed acid measurements were used and for $\mathrm{Al}_{2} \mathrm{O}_{3}, \mathrm{~B}_{2} \mathrm{O}_{3}, \mathrm{CaO}, \mathrm{Cr}_{2} \mathrm{O}_{3}, \mathrm{CuO}, \mathrm{Fe}_{2} \mathrm{O}_{3}, \mathrm{~K}_{2} \mathrm{O}, \mathrm{Li}_{2} \mathrm{O}, \mathrm{MnO}$, $\mathrm{NiO}, \mathrm{SiO}_{2}, \mathrm{TiO}_{2}$, and $\mathrm{U}_{3} \mathrm{O}_{8}$ the fusion measurements were used. Using this protocol, 4 of 6 measurements for eight M-14 calibration blocks were selected, and when the 8 sets of 4 samples were evaluated against the PCCS MAR constraints, they met all of the constraints except for the lower sum of oxides. Three of the 8 calibration blocks failed this PCCS constraint for the M-14. For completeness, the M-13 measurements were used to evaluate SME samples for its eight available calibration blocks, and none of these blocks failed the lower constraint for sum of oxides. As discussed in this report, the sum of oxides for an individual SME sample is expected to fail the lower limit for this constraint twice as often for the M-14 as compared to the M-13. Thus, use of the M-14 may put more pressure on the DWPF Laboratory to repeat their analytical process to support SME acceptability decisions than use of the M-13. The waste loadings determined from the M-14 measurements were on average about 1 point below those determined from the M-13 measurements for these calibration blocks. For sludge/frit systems that are not durability limited, there is high confidence that adequate protection from a poor decision (due to measurement uncertainty) regarding the glass quality of the SME samples is provided by the buffer between the $\Delta \mathrm{G}_{\mathrm{p}}$ value derived from the SME samples and the PAR limit for durability. 
In the discussions above, an array of issues associated with the viability of the M-14 for use as a production ICP at DWPF has been addressed. No roadblocks were encountered at any point in this discussion for such use of the M-14. While additional work is needed to fully integrate the M-14 as well at the M-13 into DWPF's operational systems, use of the M-14 ICP will be adequate for sludge/frit blending and will lead to reliable SME acceptability decisions for product quality. For a sludge/frit system that is limited by a process property prediction such as viscosity for liquidus temperature as waste loading is increased, the SME blending strategy can be adjusted to lessen the impact of an incomplete definition of the M-14's MAR on the acceptability decision by PCCS until such time as the complete definition can be determined. The same conclusion was reached for the M-13 as it was qualified for use as the production ICP at DWPF. A task is currently underway to address this issue. It should be noted that the evaluations presented in this report result in no changes, nor recommendations for changes, to PCCS.

\subsection{REFERENCES}

[1] Feller, M. T., "Leeman Qualification Test Plan for M-14 ICP," CBU-WLS-2004-00020, November 11, 2004.

[2] Pennebaker, F. M., “Leeman Qualification Test Plan,” CBU-WLS-2004-00005, March 29, 2004.

[3] Melton, W. L., "Technical Task Request: Statistical Analysis for DWPF Laboratory Qualification of the New Leeman ICP for Covariance Matrix Update (U)," HLW/DWPF/TTR-2004-0017, Revision 1, December 12, 2004.

[4] Edwards, T. B., "Task Technical \& QA Plan: Statistical Analysis for DWPF Laboratory Qualification of the New Leeman ICP for Covariance Matrix Update (U)," WSRC-RP-200400596, Revision 1, December 7, 2004.

[5] Brown, K. G., R. L. Postles, and T. B. Edwards, "SME Acceptability Determination for DWPF Process Control (U),"WSRC-TR-95-000364, Revision 4, August 30, 2002.

[6] Chen, J. N., "SME Acceptability Evaluation for Sludge Batch 3," CBU-WSE-2004-00031, March $1,2004$.

[7] SAS Institute, Inc., JMP®: Statistics and Graphics Guide, Version 5.0, SAS Institute, Inc., Cary, NC, 2002.

[8] Peeler, D. K. and T. B. Edwards, "Projected Operating Windows for Various Sludge Batch 2/3 Blends: A Progression from a PAR to as MAR Assessment," WSRC-TR-2003-00509, Revision 0, November 30, 2003.

[9] Jantzen, C. M., J.B. Pickett, K.G. Brown, T.B. Edwards, and D.C. Beam, "Process/Product Models for the Defense Waste Processing Facility (DWPF): Part I. Predicting Glass Durability from Composition Using a Thermodynamic Hydration Energy Reaction Model (THERMO)," WSRC-TR-93-672, Revision 1, Volume 1, September 28, 1995.

[10] Edwards, T. B., "Implications of the Statistical Review of the Side-by-Side Comparisons of DWPF's ICPs,” WSRC-TR-2004-00379, Revision 0, July 2004. 